\title{
Working
}

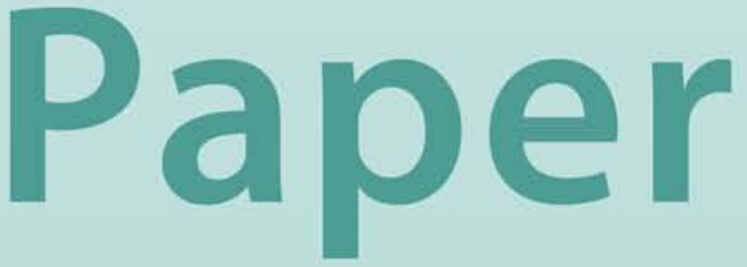




\section{Introducing Financial Management Information Systems in Developing Countries}

Jack Diamond and Pokar Khemani 


\title{
IMF Working Paper
}

Fiscal Affairs Department

\section{Introducing Financial Management Information Systems in Developing Countries}

\author{
Prepared by Jack Diamond and Pokar Khemani
}

October 2005

\begin{abstract}
This Working Paper should not be reported as representing the views of the IMF. The views expressed in this Working Paper are those of the author(s) and do not necessarily represent those of the IMF or IMF policy. Working Papers describe research in progress by the author(s) and are published to elicit comments and to further debate.

In the past decade, developing countries (DCs) have been encouraged to reform their public expenditure management systems and have increasingly embarked on major projects to computerize their government operations. Most popular among these have been projects to computerize government accounting and payment operations, by introducing government financial management information systems (FMISs). This paper investigates the reason for almost universal failure to implement and sustain FMISs in DCs. It starts with a review of the "received wisdom" in implementing these projects, and then analyzes problems in its application in the DC context to identify key factors to explain why FMIS projects have been so problematic. Based on the identified negative factors, suggestions for addressing them are offered in the hope of improving success rates.

JEL Classification Numbers: E6, M4, O5
\end{abstract}

Keywords: Financial Management Information System (FMIS), Public Expenditure Management, Functionality

Author(s) E-Mail Address: JDiamond@imf.org, PKhemani@imf.org 
I. The Importance of Financial Management Information Systems (FMISs)......................... $\underline{3}$

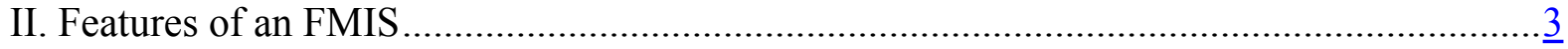

III. Strategic Framework for Introducing an FMIS in a Developing Country........................ 1

IV. Requirements for Introducing an FMIS …........................................................... $\frac{8}{9}$

A. Project Management ...............................................................................

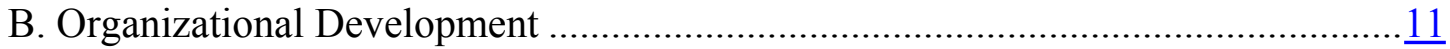

C. Parallel Reforms and Improvements to Business Processes .................................12

V. Country Experiences with the Implementation of FMISs …................................13

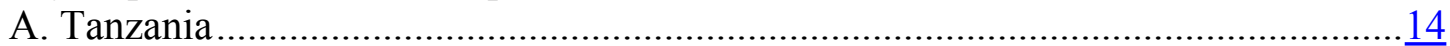

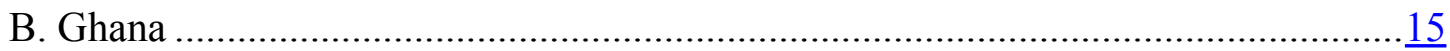

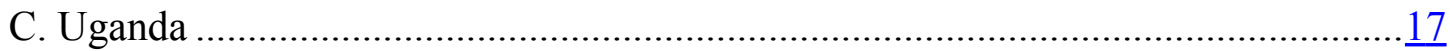

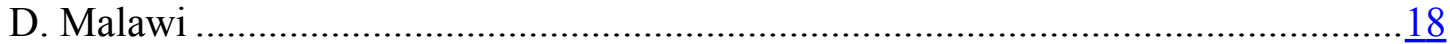

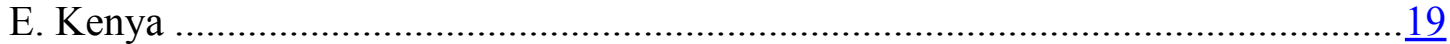

VI. Why Do FMIS Projects Stall in Developing Countries? ............................................20

VII. Preconditions for Development of an FMIS ….................................................. 24

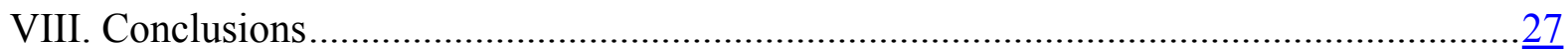

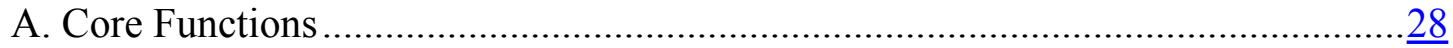

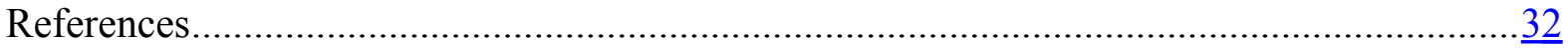

Figures

1. Institutional Framework, Processes and Information Flows............................................ 6

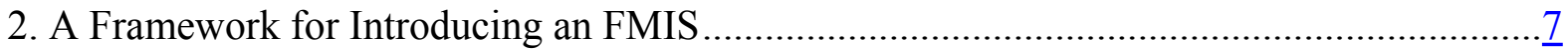

Boxes

1. Attributes of a Well-Designed FMIS

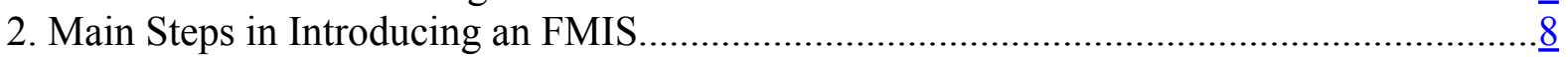

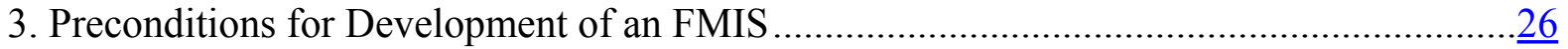

Annex

The Functions of Different Modules in a Typical FMIS .................................................2 


\section{ThE IMPORTANCE OF FinANCIAL MANAGEMENT INFORMATION SySTEMS (FMISs)}

In most developing countries (DCs), budget execution and accounting processes were/are either manual or supported by very old and inadequately maintained software applications. This has had deleterious effects on the functioning of their public expenditure management (PEM) systems, that are often not adequately appreciated. The consequent lack of reliable and timely revenue and expenditure data for budget planning, monitoring, expenditure control, and reporting has negatively impacted budget management. The results have been a poorly controlled commitment of government resources, often resulting in a large buildup of arrears; excessive borrowing, pushing up interest rates and crowding out private-sector investment; and misallocation of resources, undermining the effectiveness and efficiency of service delivery. Further, governments have found it difficult to provide an accurate, complete, and transparent account of their financial position to parliament or to other interested parties, including donors and the general public. This lack of information has hindered transparency and the enforcement of accountability in government, and has only contributed to the perceived governance problems in many of these countries.

In light of these adverse developments, it is perhaps not surprising that many DCs have pressed for, or have been pressed into, adopting financial management information system (FMIS) projects to strengthen their PEM systems. The establishment of an FMIS has consequently become an important benchmark for the country's budget reform agenda, often regarded as a precondition for achieving effective management of the budgetary resources. Although it is not a panacea, the benefits of an FMIS could be argued to be profound. First, the improved recording and processing of government financial transactions also allows prompt and efficient access to reliable financial data. This supports enhanced transparency and accountability of the executive to parliament, the general public, and other external agencies. Second, an FMIS strengthens financial controls, facilitating a full and updated picture of commitments and expenditure on a continuous basis. Once a commitment is made, the system should be able to trace all the stages of the transaction processing from budget releases, commitment, purchase, payment request, reconciliation of bank statements, and accounting of expenditure. This allows a comprehensive picture of budget execution. Third, it provides the information to ensure improved efficiency and effectiveness of government financial management. Generally, increased availability of comprehensive financial information on current and past performance assists budgetary control and improved economic forecasting, planning, and budgeting.

\section{Features OF AN FMIS}

In terms of terminology, an FMIS usually refers to computerization of public expenditure management processes including budget formulation, budget execution, and accounting with the help of a fully integrated system for financial management of the line ministries (LMs) and other spending agencies. The full system should also secure integration and communication with other relevant information systems. Because of the integration requirement, the FMIS is commonly characterized as an integrated financial management information system (IFMIS). Unfortunately, using the term "integrated financial management 
information system" can sometimes be erroneously interpreted as describing a system that can capture all the functional processes, and the relevant financial flows, within public expenditure management. However, the complexity of information systems within the government sector is, to a large extent, due to the multiplicity of functions and policy areas. In many functional areas specialized information systems are in place and will still be required even with the implementation of an FMIS. It should be noted that in this paper the term FMIS has been used generically to include an IFMIS.

As the name implies, there are, and should be, three guiding characteristics for a well-designed FMIS:

\section{- It is a management tool}

When developing an FMIS it is important that it cater to management needs - not just those of the central agencies, but also line agencies. Moreover, as a management tool it should support the management of change. It must be viewed as an integral part of budget system reform-hence not be designed just to meet present requirements, but also to support those needs that are likely to arise as parallel budget reforms are implemented.

\section{- It should provide a wide range of nonfinancial and financial information}

As a tool of management it should provide the information required for decision making. For this purpose it is anchored in the government accounting system, and should be designed to perform all necessary accounting functions as well as generate custom reports for internal and external use. However, this does not mean that it should exclusively concentrate on financial information. Managers will require other nonfinancial information. For example, personnel information such as numbers of employees, their grade within the organizational structure and rates of remuneration. For performance-based budgets, performance information will be important to managers, such as the identification of programs, the objectives or outcomes of programs, the types of goods and services produced, as well as indicators by which to judge the efficiency and effectiveness of programs.

\section{- It is a system}

Its role is to connect, accumulate, process, and then provide information to all parties in the budget system on a continuous basis. All participants in the system, therefore, need to be able to access the system, and to derive the specific information they require to carry out their different functions. The converse is also true, if the FMIS does not provide the required information - that is, has not the right functionality - it will not be used, and will cease to fulfill its central function as a system. Further, by automating procedures and internal controls, it strengthens financial controls and promotes accountability. Box 1. broadly describes the attributes of an FMIS. 


\section{Box 1. Attributes of a Well-Designed FMIS}

The FMIS should:

- $\quad$ be modular, and capable of progressive upgrading to cater to future needs;

- $\quad$ offer a common platform and user interface to the stakeholders in different agencies responsible for financial management, for adding to and accessing the information database (in its absence each agency will have the incentive to develop "its own" FMIS to meet its currently perceived needs);

- maintain a historical database of budget and expenditure plans; transaction data at the highest level of detail; cash flows and bank account operations including checks issued, cancelled, and paid, cash balances and floats;

- $\quad$ have dedicated modules to handle monthly, rolling, short-term (one to three months) and longer-term (three months to end of year) forward estimates of revenues, and expenditures prepared by agencies, and corresponding estimates of the resulting cash flows;

- $\quad$ have built-in analytical tools to offer trend analysis of various elements of fiscal operations to permit a forward look at the emerging events bearing on the fiscal stance;

- compile formal government accounts from the database of authorizations and cash allocations, primary revenue and expenditure transactions of the agencies; and treasury operations, avoiding the need to duplicate data entry for accounting purposes;

- $\quad$ enable real-time reconciliation of parallel but related streams of transaction data -at the agency level: checks issued with those paid by the banks; at treasury: receipts from banks with the checks paid by taxpayers; cash balances reflected in the agency ledgers with the cash balances in the banks;

- $\quad$ mechanize all possible routine tasks at the central and spending agencies-generating various forms/authorizations, checks, outputting hard copies of key registers and statements, etc.; and

- $\quad$ be flexible enough to provide user-defined management information, aggregated at the desired level of detail, from the database.

Although the FMIS does not capture all the information flows, adopting a comprehensive approach in the development of the project is fundamental to ensure that all functional interdependencies are identified, hence securing the capture of all related information flows. Figure 1 sets the FMIS in a broader context of interrelated information systems, and illustrates the main functional processes from medium-term planning and budget preparation to budget execution and accounting. 
Figure 1. Institutional Framework, Processes and Information Flows

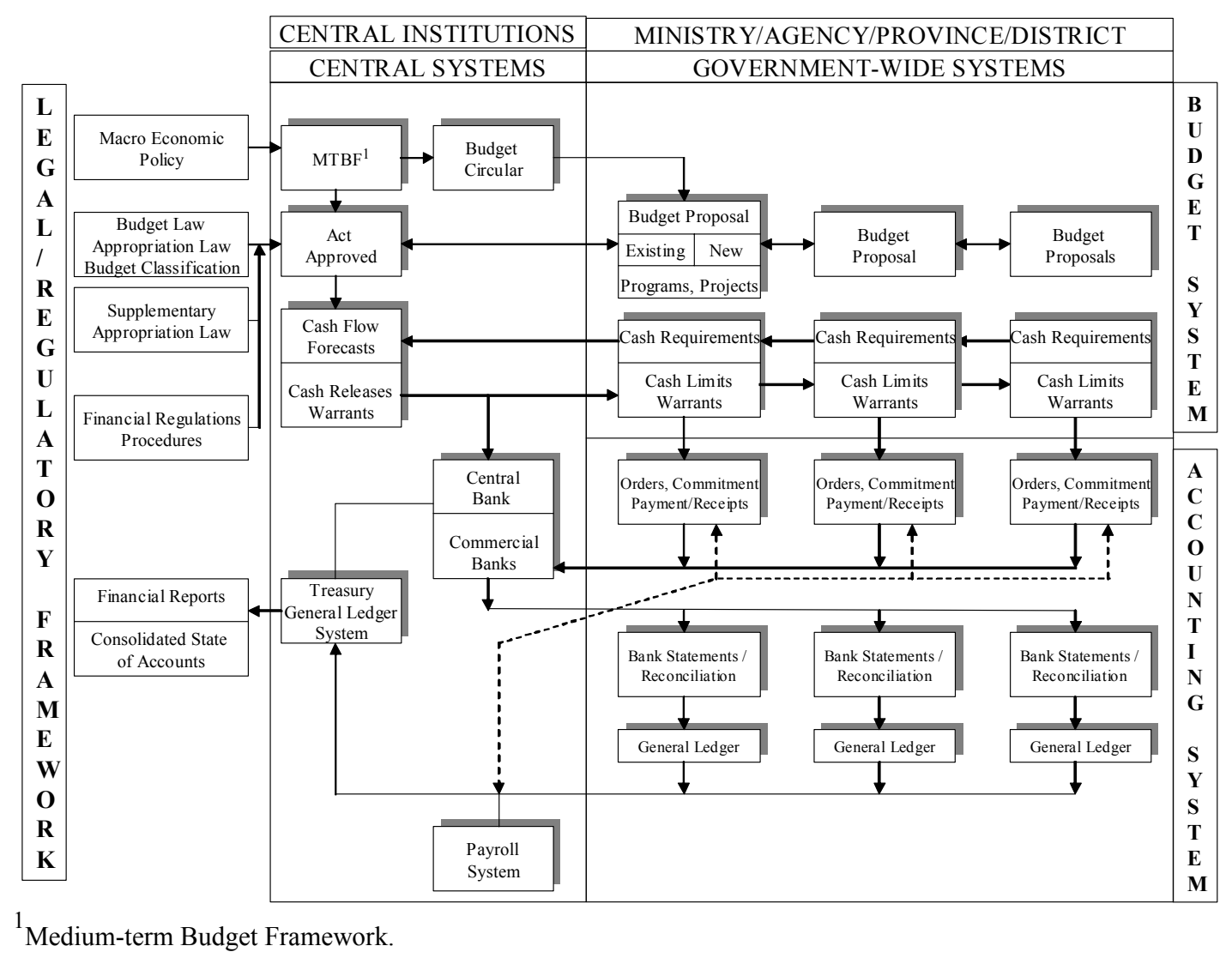

An FMIS will consist of several elements with different functions. In the description that follows, the term "module" will imply that the system is a sub-element in a FMIS. The core of an FMIS could be expected to include the following modules and systems:

- General ledger,

- Budgetary accounting

- Accounts payable

- Accounts receivable

The noncore or other modules are, inter alia:

- Payroll system

- Budget development

- Procurement

- Project ledger

- Asset module.

A brief explanation of the functions of each module of a typical FMIS is outlined in Annex I. 
It is important to set priorities for the system implementation, that will usually start with the core functions, namely budget execution, accounting, payment processing; commitment control and financial reporting.

\section{STRATEGIC FrAMEWORK FOR INTRODUCING AN FMIS IN A DEVELOPING COUNTRY}

The introduction of an FMIS in a developing country should be regarded as part of a long process of reform. This process takes years to fully implement, costs millions of dollars, and has a substantial recurring operating cost. Thus FMIS should be regarded as a major project requiring a structured project management approach. ${ }^{1}$ Viewed in this way there are four main stages in the process of introducing an FMIS, which are presented in Figure 2: preparation, design, procurement, and pilot and roll-out.

Figure 2. A Framework for Introducing an FMIS

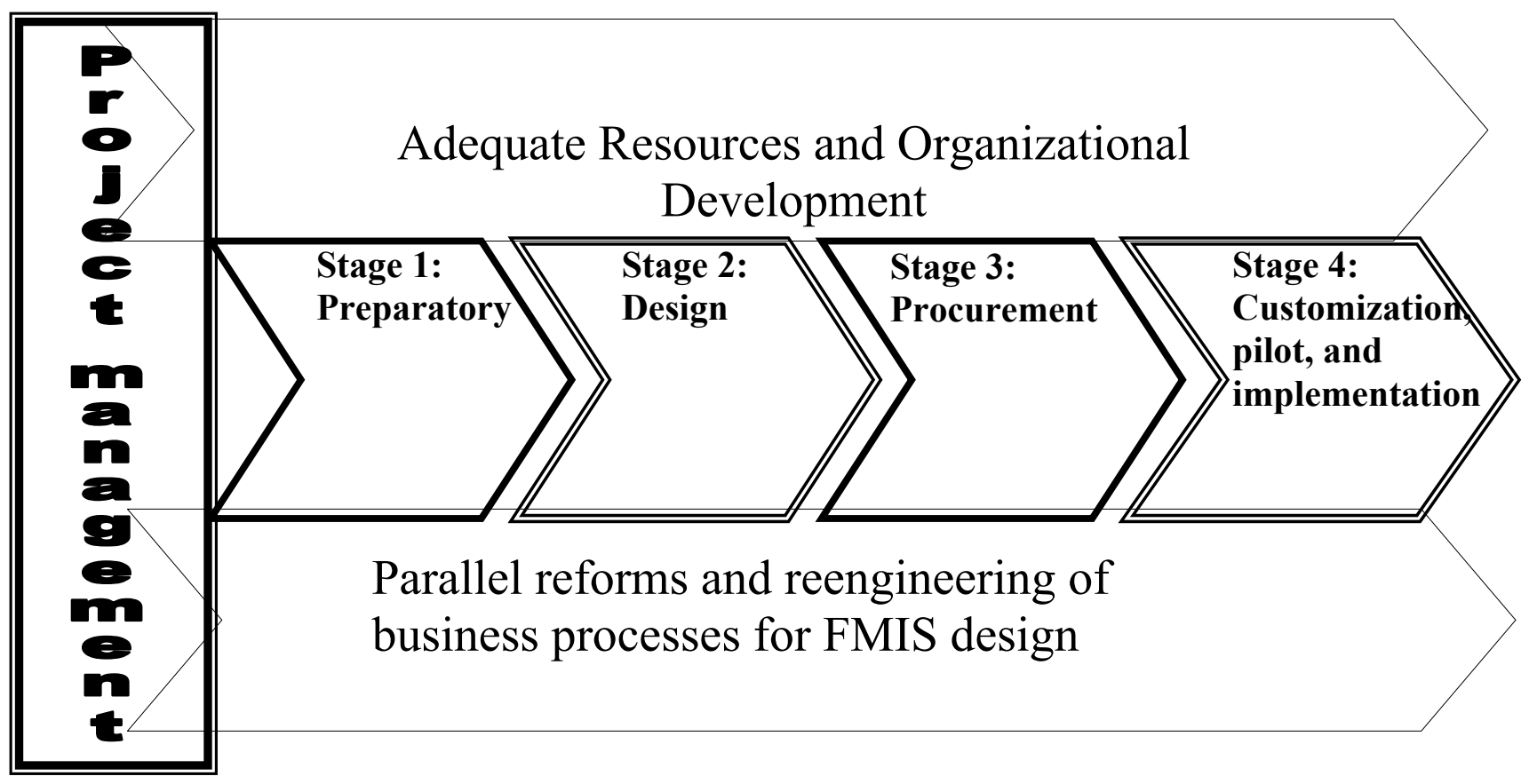

A summary of the main steps within the four stages is given in Box 2.

\footnotetext{
${ }^{1}$ The U.K. government PRINCE (Projects in Controlled Environments) methodology could be usefully applied for managing a FMIS.
} 


\section{Box 2. Main Steps in Introducing an FMIS}

Stage 1: Preparatory

- Preliminary concept design including an institutional and organizational assessment

- Analysis of the key problem areas and ongoing reform programs

- Feasibility study

- Design project and draft project proposal

- Formal approval of the project-securing government approval and donors' funding

Stage 2: Design

- Develop functional specification

- Outline information technology (IT) strategy, including hardware and organizational issues

- Prepare tender documents

Stage 3: Procurement

- Issue tenders for hardware and software and associated requirements

- Evaluation of bids and award contract

Stage 4: Implementation

- Configuration analysis and specify any additional IT, infrastructure, and communication requirements

- Detailed business process and gap analysis mapping required functionality to package and identifying and specifying detailed parameterization, customization, procedural etc, changes

- Detailed action plan for phased implementation and the pilot-run of the system

- Agreed customization and configuration of the system

- Determine training needs and conduct training of personnel

- Pilot run - parallel run of the system, resolve initial problems and evaluate system performance for roll-out

- Roll-out system to other ministries and agencies

- Phased implementation of additional modules

- Strengthening of internal system support and phasing out consultant/contractor support

These four stages describe the main process followed in the design, procurement, and implementation of an FMIS. As indicated in Figure 2, the successful implementation of this process also requires three supporting elements: sound project management; adequate resources and complementary organizational development; and parallel improvements in business procedures and practices supported by a suitable legal and regulatory framework. These supporting reforms should not be neglected in FMIS design and implementation, and without them it will not be possible to achieve the full benefits of an FMIS.

\section{REQUIREMENTS FOR INTRODUCING AN FMIS}

Given the problems often encountered in FMIS projects, it is useful to specify in some detail the essential requirements that should be met. As indicated, these requirements have been 
grouped in three categories: (i) project management; (ii) organizational development; and (iii) parallel reforms.

\section{A. Project Management}

As explained earlier, the whole process of developing an FMIS should be regarded as a major project requiring a structured project management approach. The essential elements of a sound project management are described below.

\section{Commitment, participation, and management model}

The implementation of a government-wide FMIS is a substantial undertaking for any administration, and it is essential that the participants are fully aware of the magnitude of the undertaking. Ensuring project commitment at the highest levels of the political system and bureaucracy, and continuous participation from the direct users of the system and other stakeholders, is necessary in all phases of the project.

It is also necessary that the project planning methodologies are used to plan, implement, and monitor the project, with project management responsibilities clearly identified. The management model needs to ensure broad in-house participation and involvement of all the relevant stakeholders, which usually are the ministry of finance and other central agencies, the office of the auditor general, the central bank and other banks handling government business, LMs, and local governments. The finance minister, assisted by the permanent secretary (PS/Finance) needs to take primary responsibility for overall management of the project. Since accounting is the backbone of the information system, the treasury that is in charge of this function - or in the Anglophone countries, the accountant general (AG) - is a key institution. Under PS direction, the AG is usually asked to take the lead role in the design, development, procurement, training, and implementation processes relating to the FMIS. Typically the AG must also collaborate with the head of the central information technology (IT) department in the design, development, and implementation processes.

It is critical to mobilize internal management resources. The PS/Finance and the AG should be assisted by a well-staffed project management team headed by a full-time project manager. The project manager should be supported by a full-time technical team consisting of a number of assistant project managers, with specializations in IT, budgetary and accounting processes. To ensure continuous commitment participation of top politicians and key stakeholders, it would be useful to set up a steering committee ${ }^{2}$ under the chairmanship of the finance minister to manage and coordinate the entire process of design, development,

\footnotetext{
${ }^{2}$ The steering committee will need to be representative of major stakeholders and could include permanent secretary/finance, AG, head of central IT department, budget director and heads of other finance departments, heads of selected LMs, central bank, and such other central agencies. Representatives of selected local governments could also participate in these meetings. The accountant general may function as a member-secretary for the steering committee.
} 
and implementation of the FMIS. The committee should have considerable and authoritative influence, and should meet on a monthly/quarterly basis depending on the project progress. The cabinet and the parliament also need to be informed periodically by the steering committee on the progress in the implementation of the FMIS.

Necessary measures should also be taken to strengthen the capacity in the project team as well as the AG's office and the budget office through all project phases. Simultaneously, it is also necessary to develop the necessary skills and capacity of the central IT department to provide strong support to the system. Continuity of key personnel involved in the development and implementation processes is also important for the success of the project.

\section{Strategy for use of external consultants}

In addition to in-house resources, an FMIS project requires careful choice of external technical assistance during different parts of the process. The external consultant should have extensive experience in public sector financial management including:

- The design, implementation, management, and operation of government accounting, budget, and financial management systems in a developing country environment.

- $\quad$ Experience in the management and operation of modern computerized financial systems in a government budgeting and accounting environment.

- Complementary experience in training, management development, human resource management, and organizational change in developing countries.

- $\quad$ Experience in project management and implementation, working in the advisory and training capacity in developing countries.

The external consultants need to be managed closely because they may tend to pursue their own interests. They should be required to make extensive use of local consulting or training organizations and in-house resources. The in-house resources should be fully involved in the project design and planning, technical implementation skills for both hardware and software, user support skills, etc.

\section{Comprehensive perspective maintained with a modular approach}

Although the implementation of an FMIS should be carried out in a modular way, to avoid too much strain on the capacity of organizations; it is important to keep a strategic and comprehensive view in the overall process of its planning and development. International experience in implementing FMISs indicates that these projects often lead to temporary disruptions of the normal functions in the budget and accounts departments. This disruption may last for a period of 9 to 12 months, depending on the absorptive capacities of the organizations involved. The time schedule for the entire project can be expected to be approximately four to five years after all the resources, including consultants, are appointed. 


\section{Coordination with other development projects}

The development of an FMIS in a country is typically part of a comprehensive PEM reform strategy. Other important components relating to PEM reform are the development of a medium-term budget framework (MTBF); the design, procurement and implementation of a payroll and personnel administration system; and the development of an auditing system. In addition, there are some other initiatives for donor funded projects in individual LMs and local governments. It is essential that all of these initiatives be coordinated at a senior central level, so as to avoid duplication of effort and to ensure consistency of outputs. It is also equally important to relate PEM reforms to other reforms in the public sector and the improved delivery of public services.

\section{B. Organizational Development}

At the outset of an FMIS project, it is necessary to ensure the availability of adequate financial resources. Experience has shown that the lack of sufficient resources can serve as a serious obstacle to the successful implementation of the project. Further, there is a need to clarify the future roles and responsibility for different functions. Some of these critical functions are given below:

- System and data administration. Coordinating mechanisms should be created to ensure that a common set of policies, procedures, and standards are in place for managing data and systems government-wide. This could be achieved by developing a national IT strategy, including the use of Information Technology and Information Systems (IT/IS) in the public service.

- Wide consultation and acceptance. To be successful, the organization needs to be prepared for the introduction of the FMIS and be willing to recognize and accept the benefits that the changes will bring about and the costs of implementation in their widest sense. The continuous consultation within government departments is essential. This would be possible with the help of a strong champion for the reforms.

- New job descriptions in ministries, departments, and provinces. An FMIS will induce changes in the working environment. As a consequence of these changes, new job descriptions or working processes should be formalized. The civil service should be willing to accept that the FMIS would significantly change their influence and responsibilities. As an example, the operations in the processing of financial transactions will change dramatically from manual book-keeping to automated operations and processes. The role of both the head of finance and accounting functions, and the auditors (internal as well external) will also clearly change.

- Motivation. Defining and deciding upon new structures and working practices is one thing, but implementing them is another. The challenges in organizational development are multiple. For successful implementation, the stakeholders need to 
participate and be motivated. Motivation and support for the decision of implementing the new FMIS are critical. Participation, information, and adequate training will often strengthen this support.

- Training. The training for the staff will not only include training in use of the FMIS for their respective operations and functions, but also training in the new legal and regulatory framework, the new codes and classifications, and the new business procedures put in place. In the initial stage of implementation, there is a need to develop new practices, and the associated training requires a great deal of innovation and tailoring to the specific features and capacity of the organization. A large proportion of the training should be on-the-job training, and be focused on "super-users." This implies decentralized on-the-job trainers deployed throughout the implementation period. User support is also necessary as a permanent service.

- $\quad$ Change management. The FMIS steering committee needs to develop a change strategy and establish a clear and agreed approach and timetable for implementing the various changes associated with the system. Implementation needs to be phased and flexible, and it is necessary for the ministry of finance to take a lead coordinating role in the whole process. Donors are inevitably required to provide technical and financial support for the entire process.

\section{Parallel Reforms and Improvements to Business Processes}

Another significant concern is that without the essential PEM reforms in place, or in the process of being implemented, no major gain will accrue from an FMIS. There is little advantage in introducing an FMIS that merely follows existing PEM working processes and practices. Restructuring of working processes and practices requires new procedures to be formalized and unified throughout the government. In developing countries there often is a lack of financial discipline, which also represents an important challenge. An FMIS is effective only if the underlying budgetary and accounting systems are robust and well managed.

At the same time an FMIS can be a vehicle for change. Experience indicates that an FMIS will induce several reforms in existing systems, including:

- $\quad$ Structure of the budget and the accounts. Introducing an FMIS necessitates unifying the codes and classifications (both the budget classification and the chart of accounts). These should be maintained at a central level. The reporting requirements are the basis for defining the structures of these codes and classifications. The new budget classification structure and chart of accounts should be compliant with the classification framework in the IMF's Government Finance Statistics Manual 2001 (GFSM 2001). 
- Main budgeting and accounting principles. Typically, a number of DCs use a single-entry accounting system in a manual mode, with the budgeting and accounting system on a cash basis. Off-the-shelf systems are normally designed for accrual accounting. With the implementation of an FMIS, financial transactions will be entered into the accounts payable and accounts receivable modules with the due dates, thus allowing for a gradual move toward an accrual basis. The DCs could take a step toward modified cash basis accounting, while keeping the budget on a cash basis in the early stages of implementing the FMIS.

- Cash management. To ensure that the budget and accounts are comprehensive, it is essential that all the cash flows be channeled through the FMIS, and hence that all transactions, both receipts and payments, are processed by the FMIS, including the payroll payments. The FMIS could also aim at rationalizing the government banking arrangements and establishing a treasury single account for optimizing the management of government cash balances. ${ }^{3}$

- Control structure. The design of the FMIS should introduce an improved system of internal and external controls for financial management. The internal controls regulate the cycle of recording, analyzing, classifying, summarizing, communicating, and interpreting financial information. The internal audit function helps the management in evaluating and assessing compliance with these controls. The external control system is exercised through external auditing carried out by the supreme audit institution.

Legal framework. While designing the FMIS, it is necessary to review the regulatory and legal framework and agree on the necessary modifications to the overall framework for government fiscal management. A legislative framework (Constitution, Finance Act and Regulations) needs to include: (i) the roles and responsibilities of the treasury, ministry of finance (MOF), other ministries, and other stakeholders responsible for the control and management of public finance; (ii) the main form of government funds, receipt and custody of public funds, the annual process, submission and approval of estimates and the procedures for release of funds; (iii) the basis of accounting and the form of annual accounts for audit and presentation to Parliament; and (iv) asset management and control; borrowing and investment.

\section{COUNTRY EXPERIENCES WITH THE IMPLEMENTATION OF FMISS}

Given the extensive requirements for successful implementation of FMIS projects, it is perhaps not surprising that these have proved particularly demanding on DC administrations. A small sample of project experience in Anglophone African countries highlights some of the critical factors determining success or failure.

\footnotetext{
${ }^{3}$ A treasury single account (TSA) is an account or set of linked accounts through which the government receives all revenues and transacts all payments.
} 


\section{A. Tanzania}

Since 1994 the government of Tanzania has implemented an ambitious reform program to improve public sector financial management, which initially focused on introducing effective and efficient budget formulation and expenditure management systems and processes. Specifically, two projects financed by the Swedish International Development Agency (SIDA) were designed - the Government Accounting Development Project (GADP) focusing on budget execution and the Interim Budget Development Project (IBDP) focusing on budget formulation. In 1996, following chronic problems in the financial management of the government, a decision was taken to abolish all payment offices in the ministries, departments, and agencies (MDAs), and establish a central payment system, and thereby obviate the need for MDAs to have individual bank accounts.

In 1998/99, the government decided to introduce an Integrated Financial Management System (IFMS) in ten selected MDAs. Under this system, a central server was placed at the treasury (in the Office of the Accountant General (AG)) to which users were connected by a dedicated network. Also work stations were provided for each of the MDAs from which they could access the system. Each MDA had its own database held in the omnibus database in the central server. MDAs' transactions automatically update the database in real time, and thus the general ledgers reflect the real position of balances at any particular point. By the end of 2000 there were over 500 users of the system at more than 85 sites throughout Tanzania. The system has now become the generic public sector financial management system used by the entire public sector. At the local government level, the system has been introduced to 32 local authorities, and a roll-out to an additional 30 authorities was expected to be completed by the end of 2004 .

The software package for the IFMS is a medium-sized financial management and accounting package (Platinum SQL Financials from EPICOR). At present, the IFMS is only using a few modules, namely General Ledger, Accounts Payable, Accounts Receivable, Cash Management, Purchase Order, Multi-currency, Budget Module, Foreign exchange report writer, and Crystal report writer. The accounts are essentially maintained on a cash basis, though the authorities are planning to use other modules like Asset and Inventory Management, and are working toward accrual accounting.

The benefits of the IFMS have been extensive, with the restoration of expenditure control and improved levels of transparency and accountability. The Commitment Control System has led to the elimination of overspending, and a substantial reduction in domestic arrears. A number of government bank accounts have been reduced to treasury single accounts maintained at the central bank, and the lag in reconciliation with banking data has been reduced from up to two years to automatic reconciliation on a daily basis. Comprehensive and fully reconciled fiscal data and reports are available on a continuous basis. 
Currently, the IFMS in Tanzania appears to be the most successfully implemented system in Anglophone African countries. Its implementation was distinguished by:

- An initial review of the PEM processes affecting budget execution, and the introduction of an improved expenditure control framework and chart of accounts;

- $\quad$ Embedding the reform process in the MOF combined with an emphasis on capacity building, particularly in the AG's department, through training, restructuring, and computerization;

- $\quad$ Revising, developing and managing enabling legislation, accounting principles, systems and organizational arrangements necessary for the management of government budgetary and accounting systems; ${ }^{4}$

- $\quad$ Selecting a mid range commercial software package, supported by a high quality local consultancy company, an EPICOR partner, that provided a strong support to the implementation process including training;

- $\quad$ Availability of adequate donors' resources, combined with very experienced international and local consultants;

- $\quad$ A solid backing at the political level, which trickled down to the management level; with both political and management commitment being strong throughout the entire reform process.

In Tanzania both the authorities and donors perceive the IFMS as a critical tool for achieving accountability in the public sector. Donors are now more receptive to the idea of using government systems to channel funds than ever before. However there is a need to consolidate and deepen the system and build the capacity to ensure its long-term sustainability. The system is primarily performing basic budgeting and accounting functions, and other modules like Asset Management and Inventory Management need to be implemented. Further, the system also needs to be interfaced and achieve integration with other main systems like Personnel Management and Debt Management systems (see Annex ).

\section{B. Ghana}

The government of Ghana launched an ambitious multi-faceted Public Financial Management Reform Program (PUFMARP) in 1996, which aimed to introduce

\footnotetext{
${ }^{4}$ To underpin the implementation of the IFMS process, a new Public Finance Act was enacted in 2001, supported by new financial regulations and a Procurement Act.
} 
comprehensive reforms to the budget and expenditure management processes. The main components of the PUFMARP include the introduction of a medium-term expenditure framework (MTEF) and the development of a computerized government financial management information system, termed the Budget and Public Expenditure Management System (BPEMS). In the early years of the reform program, there was a mismatch between the (fast) rate of progress with the MTEF and the (slow) progress on the BPEMS, The faster development of the MTEF, relative to the BPEMS, caused significant accounting and reporting problems. The new chart of accounts introduced by the MTEF was not coordinated with a similar change in the then existing accounting system, although this was rectified after a period of almost two years. However significant progress has been made in strengthening the budget and expenditure management processes over the past five years. In particular, the authorities have progressed from satisfying 1 of 15 Heavily Indebted Poor Countries (HIPC) Assessment and Action Plan (AAP) benchmarks in 2001, to meeting 7 of 16 benchmarks in 2004, including building a sound regulatory and institutional framework under PUFMARP.

In Ghana, the experience of the design, development, and pilot implementation of the BPEMS has not been satisfying. In the design of the BPEMS, the existing manual budget execution and accounting processes seem to have been automated to a large extent, without consideration of whether there was a better and more efficient method of achieving the required result. The original plan to roll out the system by the end of fiscal year 2001 was not achieved due to a number of factors. After considerable delays, the system was installed, on a pilot basis, at the MOF and the Controller and Accountant General's Department (CAGD) in January 2003. The roll-out for additional ministries of Education and Health (planned before the end of 2003) was carried out in March/April 2004.

Despite substantial time spent in developing and customizing the software application, ${ }^{5}$ the pilot implementation and the roll-out of the system has not progressed well. The MOF and the CAGD are not fully satisfied with the BPEMS reporting system, and this has been a major area of dispute between the government and the software team. ${ }^{6}$ There were also problems with the new managers (Close Communications) hired by the government for implementing the system.

The overarching concern is the significant delay, and limited involvement and ownership of the BPEMS by the various stakeholders in the design and development of the BPEMS. Somehow, the development process was largely driven by consultants and donors in the formative period of the project. The BPEMS had to be restructured several times, and

\footnotetext{
${ }^{5}$ The Oracle Financials software application was chosen for the BPEMS. The Oracle contractor demobilized its team twice, for a number of reasons.

${ }^{6}$ The Oracle team has not been able to make much progress in this area because of lack of clear specifications on the reporting requirements, and they have not been able to get authorities' approval of the design of various reports.
} 
encountered significant design and implementation problems and delays. The project implementation unit was also restructured several times, and there have been a number of changes in the program coordinator and program manager. Local capacity and know-how has always been and is still the major issue, and the government still relies on the assistance of local vendors. ${ }^{7}$ Consequently several significant issues need to be addressed before BPEMS can be made fully functional and rolled out.

\section{Uganda}

The government of Uganda is in the process of implementing a comprehensive financial management reform program to improve the budget and expenditure management processes at the central and decentralized government levels. In the early years, for a number of reasons, there were considerable delays in the completion of the design and development phase of the FMIS. Finally, the procurement and evaluation process was completed in February 2003 with the award of a contract ${ }^{8}$ for the provision of a turnkey solution including hardware, application software, a Wide Area Network (WAN), and supporting training/change management.

The implementation of the system began in March 2003 with the mapping and necessary configuration followed by user acceptance and testing operations in February 2004. The pilot implementation phase is currently in progress in six line ministries and four local governments. The pilot implementation covers the core modules of the application, namely Budget Management, Purchase Order, Accounts Payable, Accounts Receivable, Cash Management, General Ledger, and Financial Reporting. The software package is essentially accrual based; however the system provides a facility to allow the generation of cash based year-end financial statements to meet the audit requirements.

An assessment of the pilot implementation is in progress before the system is rolled out to other line ministries. The pilot-run has brought out a number of issues in the system functionality, as well as treasury procedures, and these need to be resolved before closing the pilot phase.

The roll-out ${ }^{9}$ has been planned in two phases - the second phase will cover all line ministries and six additional local governments; and the third phase will cover the remaining local governments. The full implementation may take another three to four years. It is necessary to complete the roll-out of the system to the whole government and ensure long term sustainability to reap the full benefits of the system by: (i) ensuring the availability of

\footnotetext{
${ }^{7}$ Unfortunately, the local firm was not sufficiently experienced to develop and implement BPEMS.

${ }^{8}$ The contract was awarded to Hewlett Packard (HP) for the entire supplies, and the application software chosen is Oracle Financial Treasury Solution.
} 
adequate resources in terms of staff capacity and maintenance budget, and (ii) progressively extending and deepening the functionality and utilization of the system.

\section{Malawi}

Since 1995, the government of Malawi has introduced a number of initiatives to improve public expenditure management, most notably the medium-term expenditure framework to improve the budget process, and the Integrated Financial Management Information System (IFMIS) to computerize the budgetary and accounting processes. In the latter case, the conceptual framework including technical specifications was completed in time. The governance structures including the steering committee, the project management team, and the implementation structure between the contractor and the government were properly set up.

The design and procurement process was completed in 2000 with the purchase of a package solution, ${ }^{10}$ and the pilot run of the customized software started in 2001 . There have been significant implementation delays, and the pilot implementation is yet to be approved by the government as successful. The pilot implementation did not follow the standard implementation methodology for this type of software. Some of the planned core modules for implementation have not been completed, while others have not been implemented at all.

This project has encountered numerous difficulties. The project implementation team was not well resourced, and was dismantled even before the implementation was completed. Change management and communication activities did not receive adequate attention, and there are inconsistent views within the implementation team and implementing ministries. The software support arrangements have changed over the years, and there have been various contracts for implementation activities. Some of the contractual work has not been properly fulfilled. The auditing aspects of the system have not been adequately planned and tested for live operations. A fast review of the system conducted by the AG with the help of an outside expert in July 2004 revealed a number of problems with the functionality of the system, so that the roll-out has been delayed until the problems have been resolved. These problems included serious deficiencies in expenditure control and tracking processes.

In general, the implementation phase has not progressed well, primarily because of clearly limited involvement and some neglect of the system by the main players, including the MOF, AG and pilot ministries. There are several significant issues to be addressed before the system can be made fully functional and rolled out.

\footnotetext{
${ }^{10}$ The CODA Financials, a medium-sized financial management and accounting software was procured for implementation of IFMIS in Malawi.
} 


\section{E. Kenya}

Since 1997, the government of Kenya has been implementing a project for the "strengthening of government finance and accounting functions" to improve financial management, accountability, and transparency of public funds. During the first two phases over the first three years, a number of diagnostic reviews were conducted and a Financial Management Information Systems Strategy was developed.

Following a procurement delay of almost two years, a contract for the purchase of the software implementation was finally awarded during late 2002. Hardware procurement was undertaken separately from the software. The pilot phase started with the setting up of core procurement and accounting modules in the treasury as well as two pilot ministries during 2003/04. The project is still in the final stages of pilot testing, and the roll-out of the system is stalled due to lack of IT and communications wide-area network architecture. Further, the implementation of the budgeting and cash management modules has been delayed for a number of reasons, and their pilot testing may commence with the 2005/06 budget cycle.

The pilot implementation has raised a number of issues. The engagement of internal and external audit staff has been inadequate, resulting in limited quality control assurance. The revised classification and chart of accounts developed for FMIS is not fully consistent with the IMF's GFSM 2001 standards, and it is necessary to eliminate inconsistencies and ensure conformity with that rubric. Further, the new classification structure is still to be adopted for compilation of the budget estimates.

Most important, the project management needs to be strengthened to ensure strategic direction, leadership, and communication. Given this situation, the fiscal year 2004/05 continues to be a pilot testing period, and being utilized for resolving the current outstanding software and IT issues. 


\section{Why Do FMis Projects Stall in DeVeloping Countries?}

The above review of past experience in introducing an FMIS in DCs gives some guidance on the key issues to be addressed, and also highlights some risks that should be avoided. The following issues, in particular, that have contributed to the limited success of FMIS projects may be worth noting in the DC context.

\section{Lack of clarity in ownership of the system and unclear authority to implement}

Public expenditure management in DCs is often segmented institutionally on vertical rather than horizontal lines. For example, even when the MOF has been given clear leadership, in Anglophone Africa it is not immediately clear who should be in charge of an FMIS projectthe MOF proper, in charge of budget management, or the Accountant General's Department, typically institutionally separated, in charge of government accounting. Both bodies could be considered as sharing a central role in the development and running of the new FMIS. The AG has significant regulatory and control functions, while the Budget Department has the dominant role in resource allocation. Although, it could be recommended that these two bodies be nominated as joint owners of the new FMIS to ensure balanced requirements for the system, at the same time joint ownership may involve a loss in accountability and real ownership of the system. To counter this it is important to get support for and commitment to the project at the highest level, say the minister of finance or his deputy. This is important not only to resolve the identified "ownership" problems, but in DCs to signal authority to push through government-wide reforms in the face of strong ministries that may feel threatened by the level of transparency that a FMIS imposes on them.

\section{Failure to clearly specify the basic functionality}

As a tool of management, an FMIS must be carefully designed to meet agencies' needs, or functional requirements. Often this original design phase is the most difficult part of an FMIS project, and does not receive the attention it merits. The functional requirements document serves as the blueprint for later phases of the FMIS project. It describes the accounting and financial management tasks the system must perform, the agency's information requirements, the operating environment, and a plan for developing any necessary programming.

\section{The failure to spend enough time on the design phase}

The functional requirements document that serves as the blueprint for later phases of the system project is critical - if wrong, it is difficult to rectify the situation later. Requirements analysis is important but tends to be an often neglected step. It cannot be rushed: for the accounting function alone, a detailed analysis can take three months to a year.

It is essential that sufficient time be taken during the planning of the project to list all user requirements for information to be derived from the FMIS. This part of the planning phase is time consuming but is essential if the building of the system is to proceed smoothly. It is usual for all users of the system initially to simply list all possible information requirements 
that they seek from the FMIS. A process of review by a panel of major users would result in a rationalizing of the requirements to a manageable level. Most important, managers should tell vendors what is required and not the other way round. It also must be recognized that it is unusual for one system to service the information requirements of all users. Although this phase is crucial to the success of the project, it cannot be allowed to run too long and encroach on the time available for the actual building of the system.

In the DC context this model approach poses some problems. Without a degree of exposure to a modern PEM environment, what can be realistically expected of managers in specifying such requirements? Often computerization is being introduced with fundamental changes to current work practices. Without prior experience, how can these managers anticipate the implications of these reforms? Can managers really be expected to plan for these changes and be capable of mapping out how their organization will get from where it is now to where it has to be in a computerized environment? Not surprisingly, in these circumstances the system requirements document is often externally generated, and much influenced by the vendors. Ideally, it should be the rule that any outside consultancy at this stage should be independent of potential vendors, undertaken by business rather than IT experts, and be developed in conjunction with the staff in the ministry to cater for local conditions. In practice in DCs there may be a lack of capacity in the host MOF to fully operationalize this approach.

\section{Failure to reengineer procedures}

Establishing an FMIS should not be viewed as merely computerizing existing procedures. Peterson et al. (1996) make the case that computerization promotes two kinds of reform: efficiency reforms that accelerate the operation of existing procedures and effectiveness reforms that change existing procedures. Strassmann (1985) contends that the real payoff from IT is when it makes organizations more effective, not simply more efficient. ${ }^{11}$ Introducing an FMIS should thus be viewed as an organizational reform. Redesigning information flows - the way those flows are processed, managed, distributed, and used for decisions - usually requires changing operating procedures. ${ }^{12}$ Inevitably, the disruption of well-established operating procedures can feel threatening to individuals who operate them, and hence it should not be surprising that such innovation is resisted.

In DCs this resistance is compounded by the lack of experience with computers. The tendency to leave system development to the computer supplier often means that these organizational issues are downplayed, and technical considerations dominate in the design and implementation of the project. The result is often a tendency for over sophistication at the expense of user friendliness. Clearly, there is a tension in going for state of the art computerization that will protect the investment against early obsolescence, as opposed to the

\footnotetext{
${ }^{11}$ Strassmann (1985, p. 127).

${ }^{12}$ Hopelain (1984, p. 150) warns that the reverse can prove fatal, that "an IT reform is not a computer recipe for an organizational problem."
} 
need for initially introducing systems that are user friendly with modest achievable goals, but subsequently capable of enhancement as user skills, familiarity, and confidence grow. Often the degree of IT sophistication has assumed too steep a learning curve for DC users.

\section{The failure to undertake parallel reforms required by the FMIS}

As argued before, the aim of an FMIS should not be to computerize the present processes but to improve work practices. The reform of business practices should be a top priority, but too often there exists a blind belief that computers will solve all problems. At a minimum, reform requires substantial groundwork to standardize manual procedures, including documentation used and processing rules across all users, redesigning and strengthening internal controls, and redesigning reports and other analytical outputs. However, more substantial reforms will take more time. For example, a new FMIS is likely to be most productive when it incorporates major upgrades in accounting. Accordingly, it may be important to review government accounting standards well in advance, and perhaps to consult national accounting bodies regarding the consistency of public and private sector standards in regard to the accounting system.

\section{The neglect to "sell" the system to agencies}

It is crucial for the successful implementation of the new FMIS that agencies accept the need for the new system and that it will provide useful information to assist managers in the management of their agencies. If the FMIS is seen as a centrally imposed tool to further control agencies, then its successful implementation will be threatened. Any agencies that currently have well-developed management information systems should be particularly targeted for selling the advantages of the new system. It is, of course, advisable that those agencies be included on the previously mentioned steering committee.

\section{Overestimating the information to be included in the system}

There is often a tendency to be too ambitious so that the intended scope of the FMIS is too wide and attempts to service all the requirements of potential users. The user specification stage discussed earlier should be used to determine what are the critical requirements for the initial version of the system and what could be left to later versions or removed from the user requirements, since they are not regarded as essential for a cross-agency FMIS.

\section{Unrealistically short project timetable}

Implementing complex FMIS projects takes time. The steps in the project are well known: preparatory requirements analysis, system design, development and testing; procurement and installation; testing of the full system in the user environment, training and conversion. As indicated, it is also well known that the time required for the completion of each step is often grossly underestimated, especially in DCs. In the past, there has been a tendency to tell top management what they want to hear. This is reinforced by top managers' short political time horizon when judging reform payoffs. While this might be one reason for the 
underestimation of time required, additionally, the inertia of development agency bureaucracies, coupled with delays inherent in the implementation of complex IT systems, is a disastrous combination. Moreover, owing to the human resource shortages faced by DCs, it will take them much longer to introduce IT systems than in more advanced countriesexperience suggests perhaps two to three times as long.

\section{The required management input is often underestimated}

The experience of advanced countries is that managing complex FMIS projects requires considerable management skill. However, this is typically in short supply in DCs. Senior managers in DCs rarely delegate responsibility and frequently are overloaded with work. Moreover, top managers may not be computer literate. The consequence is that often the binding constraint when introducing FMISs is not the technical capacity to create them but the capacity to manage them. Nor is it clear that there is always a good alignment in the incentive structure facing managers.

Bugler and Bretchsneider (1993), from the experience of IT reforms in state and local governments in the United States, concluded that the reforms were most likely to succeed if they have the following features: they are easy to use by the manager; they address an external reporting requirement by the manager; and they are confined to the manager's area of concern. These requirements are hard to attain in an DC, where top managers lack experience in computerized accounting and are therefore unable to grasp its possibilities for financial management. In DCs in the absence of computer literacy there is a tendency to leave the system development to the computer supplier, with minimal user involvement. In such an environment there is every likelihood that systems will not be user friendly, will not match the needs of the managers, and will not have a required level of management ownership.

\section{Lack of incentives for reform}

To get FMIS reforms accepted, decision makers must first be sold the idea that the benefits exceed risk. However, officials tend to be risk averse - introducing computer technology is an innovation that is perceived as risky. It is complex, it demands skilled staff, and it needs procedural changes. There is plenty of evidence of past failure. At the same time, in DCs the IT is usually introduced by expatriates, so there is room for distrust, even hostility. Second, decision makers must be convinced it is needed, i.e., that there is a problem that exists and, therefore, needs to be addressed. Basing a reform on conditions imposed by donors, as has sometimes been the case in Africa, does not increase success. Third, decision makers should recognize the urgency of the reform or the need for prompt implementation-often this perception is lacking at the top. Fourth, managers may steer away from difficult personnel issues. Almost inevitably, moving from manual systems to an FMIS allows government to fulfill the same function with fewer staff. To operate the new system will also typically require different types of skill. However, in most DCs managers in government cannot reduce staff and are severely limited in their capacity to change them. In such situations IT is 
not necessarily seen as a benefit to management, if anything from human resource viewpoint it could make their task greater and more complex.

\section{Prerequisites do not exist}

To successfully develop an FMIS, the project must be solidly based on some basic data on how the present system operates. In the DC context, information on which to base FMIS project decisions is often inadequate, although a leading cause of this is more fundamental: the lack of capacity within implementing agencies. Also there is a low level of computer literacy in the country, which must first be built up before such projects are truly viable, and sustainable, especially when applied government-wide. A computerized system's greater reliance on communications, which are admittedly poor in many DCs, may be another constraint.

It is also important to ensure that measures are taken for the project to be sustainable. It should be recognized that there are recurrent costs associated with the maintenance and operation of major FMISs that must be covered in budgets and that often are not considered. However, perhaps a greater constraint on sustainability arises from inadequate human resources. To overcome this constraint may require a major training program, which again will take time, but may not necessarily deliver the pay-off anticipated. In most DCs there is a general shortage of skilled labor, and efforts to improve skills in government are often frustrated by the migration of labor to the private sector for higher pay when workers have acquired sufficient skills.

Is it necessary to get the pay structure right before embarking on such a training program? This consideration is particularly important for in-house IT capacity, and is a concern faced by developed and developing countries alike. While most FMIS tenders specify a requirement for the vendor to maintain the system for an initial period (usually up to three years), there is also a need for IT capacity in government. Expertise is required for interacting with vendors, to maintain the system and to have adequate data management skills to optimize the system once established. Often this is insufficient to provide the required service to users. Faced with the poor pay scales mentioned previously, one solution is simply to pay retention bonuses to IT staff, another to outsource the management of IT to a local firm, and yet another is to establish a dedicated government unit to provide IT services to the public sector that allow higher salaries than the average in the public sector. None of these solutions is without problems, which tend to be exacerbated in the DC context, where there is often a lack of competition in this area. Thus, while recognizing FMISs may be the medium-term solution to many PEM problems, it is likely to be important to first spend the time in the short run in creating a solid base for success.

\section{Preconditions For DEVElopment OF AN FMIS}

A characteristic of many public sector reforms is that they are introduced in an organization with neither the willingness to accept the reform nor the technical ability to understand and implement the reform, or indeed to maintain it once introduced. As a result, the reforms 
either do not succeed or are badly delayed, and create distortions that have damaging effects, so that in many cases the reforms are eventually abandoned. The above discussion has identified some of the factors that lead to the successful implementation of an FMIS, and are summarized in Box 3. Obviously, this has some implications for technical assistance providers, like the Fiscal Affairs Department (FAD) of the IMF, which has often been called upon to support such projects financed by other donors.

Although recognizing the magnitude of the problems faced in this area, it would also appear that DCs have little option but to persevere with such projects. The FMISs will remain important to a longer-term PEM reform agenda, and it is essential that FAD and other technical assistance providers collaborate, if only to avoid the future problems that could arise if the FMISs are poorly designed, as well as to ease problems of implementation. The question to be posed is what is the optimal way of improving these projects, and what support FAD can offer in this area.

First, since these projects take time, it is most important in planning technical assistance that, even if accepted as a longer-run solution, the FMISs make allowances for the problem of filling an interim period of two to three years prior to their full implementation. In this period, it is often essential to ensure that the existing accounting and reporting systems are maintained, that business practices in the MOF are adjusted to function in the new computerized environment, and to ensure that the desired functionality of the FMIS is incorporated in its design. It seems inevitable that this work will need to continue.

Second, before projects are too advanced in preparation, a rigorous risk assessment should be undertaken to ensure that the preconditions for success exist. A judgment should be made that specific preconditions are suitable: that there is commitment of top managers, and that there are adequate project management capacity and coordination mechanisms. If not, efforts should be directed to fill these gaps before proceeding with the FMIS. Box 3 indicates the main dimensions of such a risk analysis. 


\section{Box 3. Preconditions for Development of an FMIS}

* Authorities' commitment and ownership is clear

- Clear institutional designation

- Clear authority to implement

- Active involvement, with no undue delegation to suppliers

* Preconditions are ready for reform

- Authorities prepared to reengineer work practices

- Environment encourages reform

- Sufficient skills and/or training available

- Users are "sold" on the system

- Steering group is active and representative

* Project design is sound

- Adequate time taken on design phase

- Users fully involved in specification

- Not too ambitious in scope

- Timetable is realistic

* Management of project is capable

- Adequate management skills

- Managers motivated to reform

- Full-time implementation team identified

- In-house or outsourced maintenance capacity identified, in place, and properly costed

* Adequate resources are assured

- Sufficient funds since actual costs might exceed anticipated cost

- Resource demands caused by operating two parallel systems simultaneously

- Sufficient resources for long-term operation and maintenance of the system

It is important to ensure that the above requirements are in place, in the order listed. If this will not be possible in a reasonable timeframe, a phased approach is recommended as well as the acceptance of interim solutions, if necessary.

Third, there should be a well-defined exit point for external assistance. Perhaps most value added is at the upstream stages - the initial design and testing stages — not in implementation where there should be a conscious effort to ensure local capacity exists to complete this phase.

Fourth, in that design work special attention needs to be paid to specific critical aspects of the project. Namely, that there is concurrent reform of the work practices; there are assurances that the project is not simply computerizing the existing procedures; that the accounting core of the FMIS is sound and will generate the information required for MOF management and 
fiscal analysis; that the general functionality requirements are comprehensive enough to accommodate not just present but also future needs; and that the timetable for implementation is realistic.

\section{CONCLUSIONS}

There are three main conclusions emerging from this review. First, the introduction of an FMIS in a developing country should be regarded as a component of a wider reform process. These projects, therefore, should not be viewed as isolated interventions, but should be accompanied by, and related to, other reforms in public sector financial management. It is also necessary that the FMIS objectives and outputs are both relevant and consistent with wider fiscal policy reforms.

Second, the decision to introduce an FMIS needs to be accompanied by strong commitment, sufficient manpower and financial resources, widespread internal support, and an agenda for effective change management. Unless these are in place, the chances of success are limited.

Third, the implementation strategy both in terms of functionality and number of entities needs to be phased. The benefits expected from the system develop only over time, and it will be necessary to maintain interim arrangements to facilitate various aspects of financial control and reporting.

Country authorities should be prepared for a long implementation path, and one that involves significant challenges. It will be a complex learning process for all concerned. A number of difficulties are likely to be encountered en route, but the existence of the previously indicated three conditions, along with resolute commitment of key stakeholders, should overcome these difficulties and ensure success of this worthwhile reform. 


\section{The Functions of Different Modules in a Typical FMIS}

\section{A. Core Functions}

\section{General ledger}

The general ledger $(\mathrm{G} / \mathrm{L})$ module is the foundation of an integrated FMIS. The G/L should record all financial transactions - starting with the allocation of budget funds through the commitments to the payment of goods and services. This module should provide a complete picture of assets and liabilities of the government, as well as associated financial flows. The system should be highly integrated with all other modules of the FMIS as well other systems, if any, that process government financial transactions. The system should facilitate simultaneous posting of all the transactions in the general ledger accounts and in all appropriate subledgers following the rules imposed by a chart of accounts. The system must include facilities for automatic consolidation of accounts of different budget units at different levels of government. The $\mathrm{G} / \mathrm{L}$ system must have a strong reporting facility to produce all types of financial reports, both for use by internal management and external agencies.

\section{Budgetary accounting}

This module should assist in accurate recording of the approved budget, as well as revisions to the approved budget authorized by the legislature. The system should follow the full classification of the budget, with a facility to incorporate further enhancements to classifications. In the case where the approved budget is not available at the beginning of the year, the system should allow recording of interim budget appropriations per subhead and allow for its replacement in due course by the approved budget appropriations. The system should record the transfers between appropriations and reallocations/virements between different subheads as approved by the MOF during the course of the year. A historic record of the original budget, transfers, and virements should also be maintained. The system should facilitate maintenance of cash flow forecasts, prepared on the basis of the approved budget and updated through the year based on the revisions, budget transfers, and virements. The system should link the budget classification with the standard functional and economic classifications for economic analysis purposes.

In many systems the above functions are performed by the G/L module itself, and the separate budget module is more comprehensive, dealing more with the development of budget estimates rather than merely recording the budget estimates.

\section{Accounts payable}

The main function of accounts payable $(\mathrm{A} / \mathrm{P})$ module is to process invoices and vouchers for government expenditure, authorize payments, and maintain a record of liabilities. The module must have necessary features to monitor and manage payments efficiently to utilize discounts and avoid arrears, interest payments, and penalties. In some systems the A/P ledger is the subledger of the $\mathrm{G} / \mathrm{L}$ and interfaces with all relevant systems, such as procurement. The payment 
processing should be controlled by the approved commitments and the satisfactory delivery of goods and services.

\section{Accounts receivable}

This module must be able to handle all types of inflows that are received by budget units, including nontax revenues such as sales of goods and services, as well as fees and commissions. The module should be able to produce bills, process and record receipts, and record payments.

Noncore/other modules have the following functionality:

\section{Payroll system}

Some personnel and payroll systems are integrated modules of an FMIS. Another option is to keep the payroll system as a separate system with an interface with the FMIS. The minimum requirements are that the payroll systems must contain the information needed to process payments of the payroll through the FMIS. All payments and receipts should be captured in the IFMIS. Some of the data needed are:

- Benefit items for each employee: basic salary, professional or family allowances, and deductions such as for income tax, health insurance, pensions;

- Budget information: expected increases, budget salaries for next year, overtime rates;

- Bank accounts information on employees, bank code, branch code, accounts number, etc.

\section{Cash management}

The system should assist in maintaining an up-to-date picture of the government's liquidity position and cash requirements. The system could reside in the Budget Department of the MOF, and collect data from revenue agencies on revenue collections, and debt from the debt management system. These could be supplemented by information flows from external sources like the central bank for consolidation and preparation of cash management plans. In view of the different information flows required for cash management at a central level, some of the information flows will be interfaced with the information retrieved from the IFMIS.

\section{Budget planning}

The FMIS should include functionality for preparation of annual budgets. This module should be able to exchange data with separate applications for macro-economic analysis and projections, and facilitate the top-down and bottom-up approach for the formulation of budget estimates. Hence, a separate budget preparation system with an interface to the FMIS should assist in the evaluation of the budget proposals. This system should be able to access 
and generate data from the previous years. While time-series and compatibility of codes and classifications are vital features, the budget planning system should also be supplemented with tools for assessing the actual performance of ongoing projects, evaluations, and costbenefit analysis for new proposals.

\section{Debt management}

A separate debt management system maintaining information on public domestic and external borrowings is required. This includes information on loan documents and transactions and issues of government securities. Some of the financial information from the FMIS is vital for debt management. In addition to accounting information, these systems also provide information required in the formulation of fiscal policy, such as forecasts of drawdown and debt-servicing liabilities. Payments related to government borrowings are carried out in the central debt management system. Loan receipts recorded in government accounts are processed by the central FMIS and central treasury general ledger, and are subsequently used to update the debt database.

\section{Revenue administration}

Revenue administration is generally supported by a system that has two main objectives:

- The formulation of tax and tariff policies and the subsequent collection of tax and nontax revenue; and

- The assurance that the system should assist in capturing all sources of revenue and ensuring that they are properly accounted for.

The system should interface with the G/L for updating the ledger accounts, and should also provide input data to cash management system for preparation of cash flow forecasts. The system should facilitate the monitoring and evaluation of the revenue performance against the projections and set targets for future.

\section{Purchase or procurement}

The system allows the input of commitment approval levels, records the full or partial discharge of commitments, and shows outstanding commitments at any given time. (The discharge of commitments would be controlled by the A/P module). This module should have the ability to generate local payment orders (LPOs) after the necessary checks and balances have been met. In particular, an essential feature is that the system must have the capacity to reject procurements (at the LPO issuance stage) when funds are unavailable - that is, where commitment and cash controls would be breached should the purchase proceed. 


\section{Project ledger}

This is an optional module that records the listing of projects approved, the total cost of the budget allocation for the current year, previous years' cumulative expenditures, and the balance remaining to project completion. There would need to be provision to deal with price increases and approved contract variations. This module would need to agree with the expenditure records of the cashbooks, as well as have an interface with the budget preparation module.

\section{Assets module}

This is an optional module and should record all assets purchased or built by the government, as well as their disposal when this occurs. Information in this module would come from both the cashbook and the projects modules. Government holdings in public enterprises would also be recorded here. 


\section{REFERENCES}

Allan, W. and A. Hashim, 1994, "Core Functional Requirements for Fiscal Management Systems," International Monetary Fund.

Asselin, L., 1994, Integrated Financial Management Systems: Experiences in Latin America, World Bank (mimeo) pp. 1-82.

Bugler, D.T. and S. Bretschneider, 1993, "Technology Push or Program Pull: Interest in new Information Technologies within Public Organizations" in Public Management: the State of the Art (San Francisco: Jossey-Bass).

GAO, 1987, "Critical Factors in Developing Automated Accounting and Financial Management Systems," U.S. Printing Office.

Gibson, C.F. and R.L. Nolan, 1974, Managing the Four Stages of EDP Growth, Harvard Business Review, Vol. 52 No. 1 pp. 76-88.

Hopelain, D.G., 1984, "The Structure of Information Systems Design: Five Axioms for the Management of Systems Development," in T. M. A. Bemelmans (ed) Beyond productivity: Information Systems Development for organizational Effectiveness, Amsterdam: Eslevier Science Publishers B.V., pp. 147-56

Miranda, R. and T. Keefe, 1998, "Integrated Financial Management Systems: Assessing the State of the Art," Government Finance Review, pp. 9-13.

Moussa, A. and R. Schware, 1992, "Informatics in Africa: Lessons from World Bank Experience" World Development, Vol. 20, pp.1737-52.

Murphy, P., 2002, "Road Map for Implementation of an Integrated Financial Management (Accrual Based ) System in a Developing Country Environment," (mimeo).

Peterson, S.B., 1993, Making it Work: Implementing Effective Financial Information Systems in Bureaucracies in Developing Countries," Development Discussion Paper No. 447, HIID, pp. 1-26.

Peterson, S., C. Kinyeki, J. Mutai, and C. Ngungu, 1996, “Computering Accounting Systems in Developing Bureaucracies: Lessons from Kenya," Public Budgeting and Finance, Vol. 16(4) Winter, pp. 45-58.

Strassmann, P.A., 1985, Information Payoff: The Transformation of Work in the Electronic Age, New York Free Press.

Sundh, P.O., 1989, "Future of EDP Systems in Government Financial Management," in "Seminar on Budgeting and Expenditure Control-Session Papers," Washington, D.C., November 27-December 6, pp. 78-96. 